\title{
Jahrestagung 1985
}

Die Jahrestagung 1985 fand vom 2. bis 5. Oktober in der Zähringer und Saane-Stadt Freiburg i.Ue. statt, die, an der deutsch-französischen Sprachgrenze gelegen, wegen ihrer architektonischen Vielfalt, ihrer kulturellen Offenheit und ihrer Einbettung in eine der schönsten Schweizer Landschaften mit Recht viel gerühmt wird. Nach Bern (1969) und Basel (1977) ist Freiburg i.Ue. die dritte Schweizer Universitätsstadt, die die Vereinigung als Tagungsort gewählt hat. Hans Heinrich Rupp (Mainz) führte den Vorsitz. Die Diskussionsleitung war beim ersten Beratungsgegenstand dem Vorstandsmitglied Peter Häberle (Bayreuth/ St. Gallen) anvertraut, beim zweiten Beratungsgegenstand dem Vorstandsmitglied Hans-Uwe Erichsen (Münster). In den Vorstand kooptiert war Herr Thomas Fleiner-Gerster (Freiburg i.Ue.), der als Gastgeber vor Ort mit außerordentlichem persönlichen Einsatz in kaum zu übertreffender Weise der Tagung einen glanzvollen und perfekten äuBeren Rahmen gab.

Seit der letzten Jahrestagung sind 9 Kolleginnen und Kollegen neu in die Vereinigung aufgenommen worden. Die Vereinigung zählt nunmehr 336 Mitglieder. Davon haben 179 an der Freiburger Tagung teilgenommen, viele mit ihren Ehefrauen. Der erste Vorsitzende, Hans Heinrich Rupp, konnte mehrere Schweizer Staatsrech tslehrer, die nicht Mitglied der Vereinigung sind, sowie Gäste bzw. Kollegen aus Holland, Italien, Japan, Korea und USA begrüßen, ferner Vertreter deutscher juristischer Fachzeitschriften und Verlage.

In der Mitgliederversammlung am 2. Oktober 1985 wurde der seit der Göttinger Tagung (1984) verstorbenen Mitglieder der Vereinigung gedacht: Wolfgang Abendroth, Hartwig Bülck, Ernst C. Hellbling, Wolfgang Martens und Frido Wagener. Die Vereinigung wird ihnen ein ehrendes Andenken bewahren.

Die nächste Jahrestagung wird vom 15. bis 18. Oktober 1986 in München stattfinden. Als neuer Vorstand wurden in geheimer Wahl gewählt: Hans F. Zacher, Martin Kriele und Christian Tomuschat.

Am ersten Abend wurde den Teilnehmern mit ihren Damen die Ehre eines Empfanges durch den Schweizer Bundespräsidenten Dr. Dr. h.c. Kurt Furgler in der Aula Magna der Universität Miséricorde zuteil. Der Bundespräsident, den Teilnehmern nicht zuletzt durch seine Verdienste um die Totalrevision der Schweizer Bundesverfassung bekannt, wies in seiner Begrüßungsansprache auf die Brückenfunktion von Freiburg i.Ue. zwischen den nördlichen und den lateinischen Kulturen 
hin. Auch betonte er als Aufgabe der Rechtsvergleichung, die Gemeinsamkeiten der abendländischen Kultur herauszuarbeiten. Vor Beginn des wissenschaftlichen Teils am Vormittag des 3. Oktober 1985 begrüßte der Präsident der Juristischen Abteilung der Universität Freiburg, Prof. Dr. Peter Gauch, die Teilnehmer. Am Abend desselben Tages gaben der Staatsrat des Kantons Freiburg, Herr Marius Cottier und für den Rektor der Vizerektor, Prof. Dr. Adrian Schenker, in der Ehrenhalle der Universität einen Empfang, an dem sich auch der Gemeinderat der Stadt Freiburg beteiligte. Anschließend fand ein RacletteAbend auf Einladung der Universität und der Stadt Freiburg i.Ue. statt. Musikalisch wurde er durch Volkskunst im besten Sinne des Wortes, vier Freiburger Alphombläser, umrahmt. Den Abend des 4. Oktober krönte ein „Diner aux chandelles“ im Schloß Chillon. Höhepunkt waren hier eine Damenrede in klassischer Gewandung, gehalten von Herrn Kollegen D.Chr. Dicke, und der Chor „Les Narcisses de Montreux“. Wertvolle Erkenntnisse vermittelte der Vortrag ,Freiburg, ein Staat zwischen zwei Kulturen", den der Freiburger Professor für Geschichte des Mittelalters, Dr. C. Pfaff, am Samstag Vormittag hielt. Die Tagung klang aus mit einer Drei-Seen-Rundfahrt (Murten-, Neuenburger- und Bielersee), die allen Teilnehmern wegen der landschaftlichen Reize, der ständig wechselnden Panoramen und des herbstlichen Sonnenscheins unvergeßlich bleiben wird. Das die Tagung vom 3 . bis 5. Oktober begleitende Rahmenprogramm umfaßte u.a. einen Besuch des Bundeshauses in Bern (Führung durch Alt-Bundespräsident Dr. Hans Hürlimann), des Klosters Hauterive sowie ein Orgelkonzert.

Die Freiburger Tagung war vor Ort phantasievoll geplant und hervorragend organisiert: bis ins letzte Detail. Den deutschen und österreichischen Teilnehmern schenkte sie ein unvergeßliches Erlebnis. Zwischen den Teilnehmern aus den drei deutschsprachigen Ländern dürften menschlich wie fachlich neue Brücken geschlagen worden sein: dank des besonderen genius loci Freiburgs. Großer Dank gebührt der gastfreundlichen Universität, allen voran Herm Fleiner-Gerster und seiner umsichtigen und liebenswürdigen Gattin Piera sowie den überaus hilfsbereiten Kollegenfrauen: Traute Dicke, Evelyne Krauskopf, Gretel Oser, Ursula Riklin und Anne Tercier; sie halfen vor allem bei der Gestaltung des Rahmenprogramms. Dank gebührt auch den immer präsenten Mitarbeiterinnen und Mitarbeitern Herrn Fleiner-Gersters.

Die nachstehend abgedruckten Referate wurden am 3. und 4. Oktober 1985 in der Aula Magna der Universität Freiburg i.Ue. gehalten. Dort fanden auch, jeweils an den Nachmittagen, die Aussprachen statt. 